\title{
OEBALUS PUGNAX AN ENEMY OF GRASSES.
}

\author{
BY H. GARMAN, LEXINGTON, KY.
}

THIS is one of the commonest of the Pentatomidae in Kentucky, occurring everywhere in July and August on grasses. Its constant presence and abundance on millet attracted my attention in I889, but with Podisus spinosus and other predaceous members of the family in mind, it was assumed to be there after other insects, and was not given special attention. In the summer of IS9o it was again found to be common on several species of Setaria and Panicum, - so common that as many as twenty adult bugs could be taken from a single stool of grass. This time the incongruity of a predaceous insect congregating on particular species of grasses, where there was no evident animal food, made its impression, and a brief examination was sufficient to show that the bugs were attracted by the grasses themselves, which they were puncturing, and from which they were extracting the sap. They seemed especially fond of the young spikelets, and where the bugs were abundant large numbers of the spikelets were found to be dried up, having been emptied of their contents.

On July 16 a number of the bugs were collected from Setaria glauca and Panicum sanguinale, and confined with a bunch of grass in a breeding cage, where they were observed to continue their work of puncturing the spikelets. Some individuals were coupled when taken, and on the igth of July the eggs were found to have been placed in scattered clusters of about a dozen eggs each, on the stems of grass, and on the sides of the cage. Each cluster consisted of two series, the eggs being in contact, but those of one series alternating in position with those of the other. This arrangement of the eggs accommodates them to the stems of grasses. The habit of so arranging them appea1s to be fixed, for no matter where placed the double lines were always adhered to. The eggs are pale green, and measure $.7 \mathrm{~mm}$. in length by $.6 \mathrm{~mm}$. across, the diameter being maintained to the extremities. The attached end is perceptibly convex. The free end is so little convex as to appear flat; it is rimmed, and provided with a marginal series of capitate appendages which are so small as not to be easily made out even with a good lens.

From my own observations I should have supposed $O e$. pugnax to be exclusively a vegetable feeder, but in the fourth report of the United States Entomological Commission, p. 97, I find it stated that the species has been observed attacking the cotton worm. Of course there is nothing improbable in its taking both vegetable and animal food. 

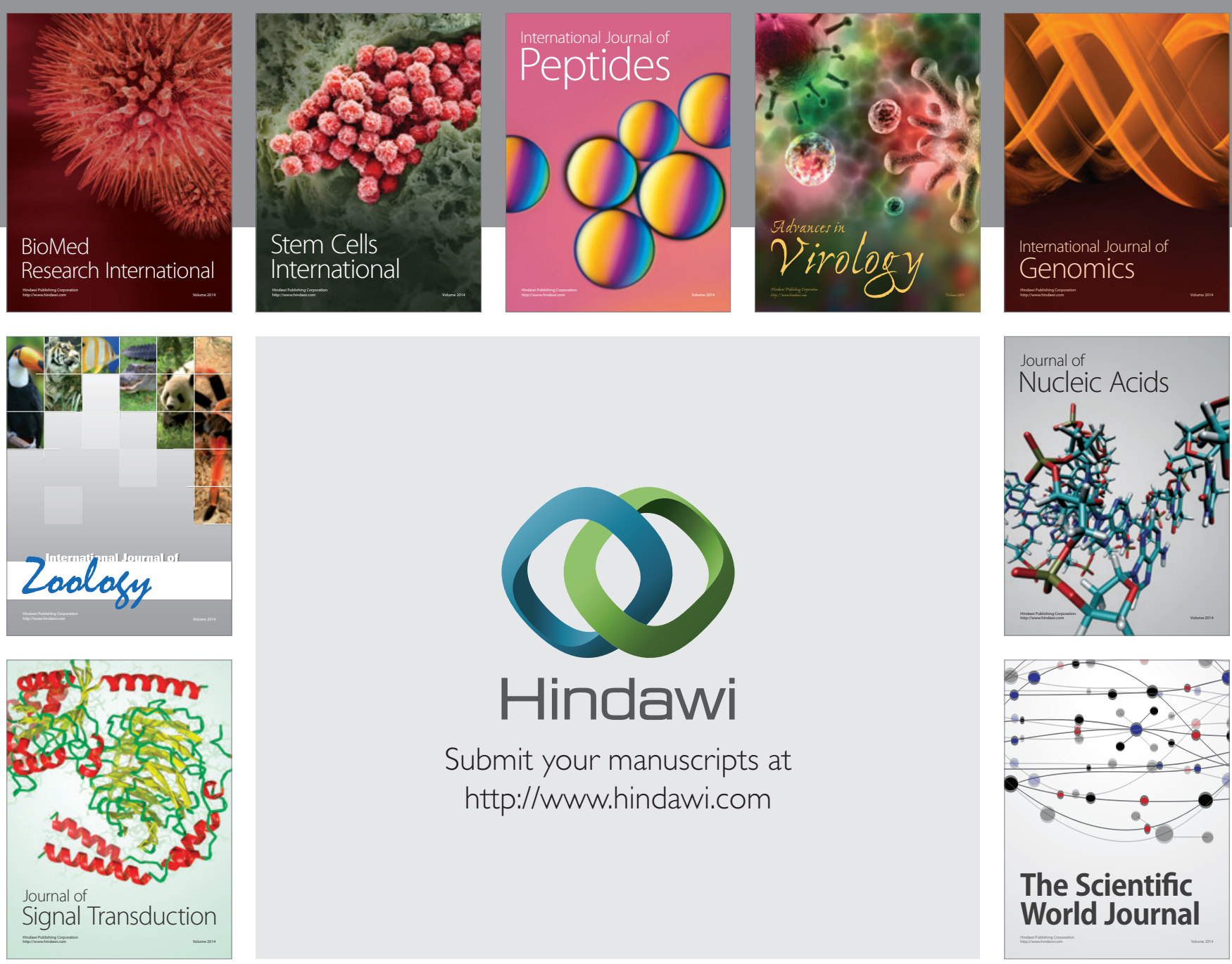

Submit your manuscripts at

http://www.hindawi.com
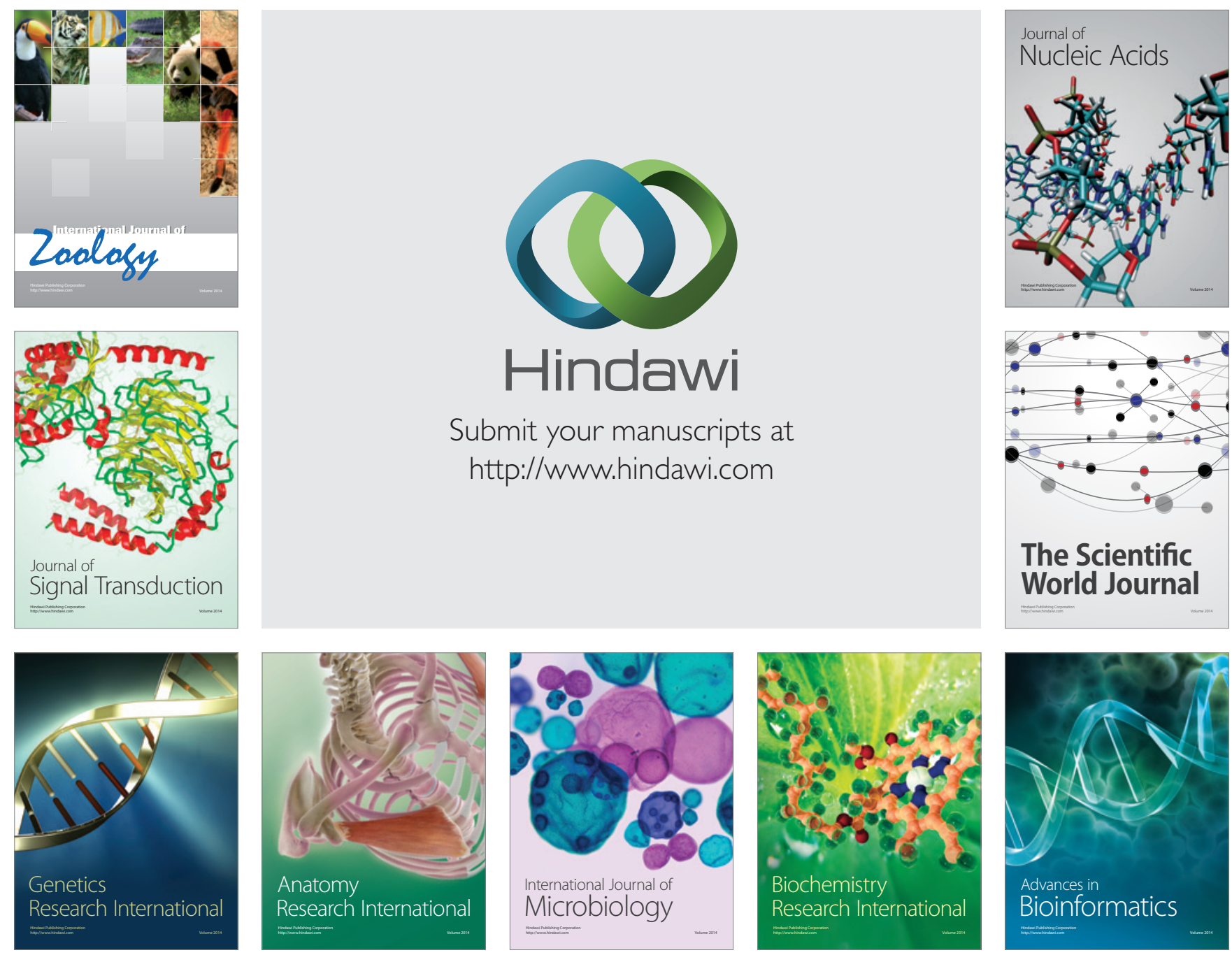

The Scientific World Journal
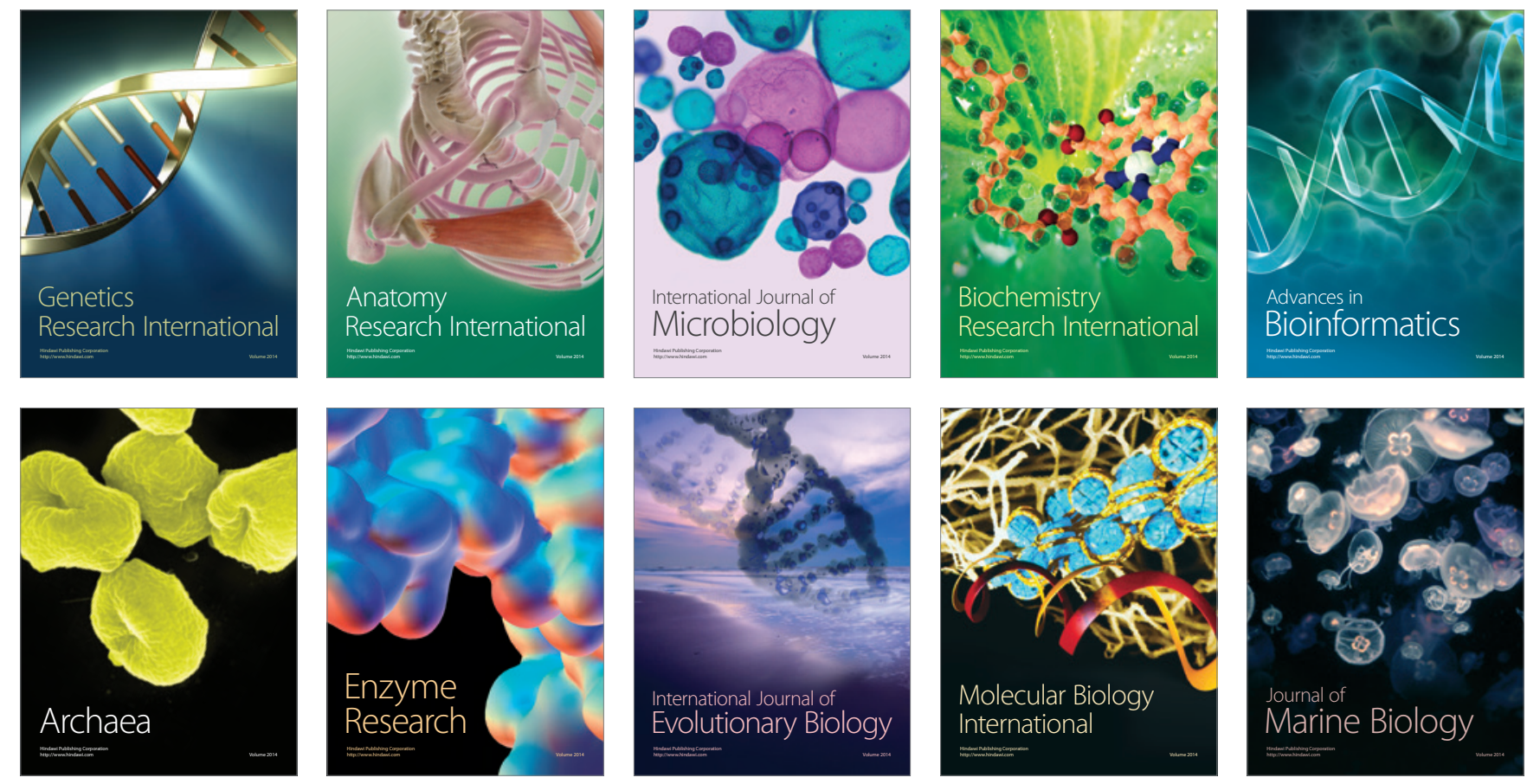